\title{
Urbanizaciones cerradas y transformaciones socioespaciales en Metepec, Estado de México
}

\author{
Teresa Becerril-Sánchez. Universidad Autónoma del Estado de México, Toluca, México. \\ José Méndez. Universidad Autónoma del Estado de México, Toluca, México. \\ Carlos Garrocho. El Colegio Mexiquense, A.C, Zinacantepec, México.
}

RESUMEN | En los últimos tiempos, nuevas formas de urbanización -específicamente, la urbanización cerrada - están rompiendo con la manera tradicional de entender el crecimiento urbano, los modelos urbanísticos, la traza, el sentido del espacio público, entre otros factores. El propósito de este trabajo es explicar lo que se entiende por urbanización cerrada y, en un caso concreto, examinar cómo dicha modalidad ha transformado los componentes socioespaciales del municipio de Metepec (México). Dicha transformación se puede identificar por la extendida presencia de conjuntos urbanos que definen y redefinen la imagen urbana en Metepec. Las urbanizaciones cerradas modifican lo que tradicionalmente se había entendido como calle, rompen su continuidad y, por ende, su movilidad, además de instalar atmósferas de miedo en esos espacios sociales. Tales aspectos son analizados de manera detallada en las diferentes secciones del documento.

PALABRAS CLAVE | barrios cerrados, distribución espacial, segregación

ABSTRACT | In recent times, new forms of urbanization are breaking up with the traditional understanding of urban growth, urban models and layout, and the meaning of public space, among others factors. These new forms of urbanization include the gated communities, which this paper aims to define and characterize, discussing how they have transformed the sociospatial components of the municipality of Metepec (Mexico). The changes can be identified by the recurrence of urban projects that currently define and redefine the urban image in Metepec. Gated communities also transform what has traditionally been understood as a street, breaking its continuity and its mobility, as well as installing atmospheres of fear in them. Both aspects are discussed in detail in different sections of the document.

KEY WORDS | gated communities, spatial distribution, segregation 


\section{Introducción}

La urbanización cerrada es una tendencia que se presenta en distintas ciudades del mundo, y que recibe distintas denominaciones: gated communities en Estados Unidos, barrios cerrados o countries en Argentina, condominios fechados en Brasil, por dar algunos ejemplos. Constituyen una forma urbana emergente, presente en diversos grados en países tan diferentes como Indonesia, Rusia, Estados Unidos, Brasil, Argentina, Sudáfrica, Turquía o Egipto. En Estados Unidos, país que lidera esta tendencia, al menos ocho millones de personas viven en gated communities" (Blakely \& Snyder, 1997, en Thuillier, 2005, p. 6). Para el caso de México, este fenómeno es más recurrente en las grandes ciudades (Instituto Nacional de Estadística, Geografía e Informática [INEGI), 2010), especialmente en las más pobladas del país; por ejemplo, las zonas metropolitanas de Ciudad de México (20 millones de habitantes), de Guadalajara (4,5 millones de habitantes, de Monterrey ( 4 millones de habitantes), de Puebla $(2,6)$ y de Toluca $(1,8)$.

Para efectos de este trabajo, se toma como objeto de estudio el municipio de Metepec (México), que forma parte de la Zona Metropolitana de Toluca y que en los últimos veinte años ha sufrido transformaciones socioespaciales muy importantes. Ellas se derivan de flujos migratorios de población de estratos medio alto y alto; de inversiones nacionales y transnacionales que han modificado el espacio urbano con la construcción de grandes centros comerciales, plazas comerciales, clubes privados; y, para el caso de la vivienda, de la oferta de urbanizaciones cerradas (Rodríguez, 2002).

Para explicar las transformaciones socioespaciales resultado de las urbanizaciones cerradas es necesario, cuando menos: a) Entender las urbanizaciones cerradas y las transformaciones socioespaciales como conceptos; b) Identificar la presencia de urbanizaciones cerradas; y c) Detectar las transformaciones socioespaciales de las urbanizaciones cerradas a partir de tres ejes explicativos: i) Las transformaciones en el aspecto físico y arquitectónico; ii) Las funciones de estas nuevas manifestaciones urbanas (viviendas, comercios, servicios, recreación, deportivos); y iii) Los cambios en las relaciones y prácticas sociales en las urbanizaciones cerradas (Enríquez, 2007).

De manera general, la presencia actual de urbanizaciones cerradas - es decir, delimitadas por bardas perimetrales - ha implicado el cambio de sentido de algunos espacios que, a lo largo de la historia, habían sido considerados como espacios públicos. Es el caso de las calles y de algunos lugares dedicados al esparcimiento, como parques y jardines, cuya privatización no solo implica transformaciones espaciales en la continuidad de la traza urbana —en el caso de la calle, se limita la movilidad y traslado no solo de los peatones, sino de cualquier medio de transporte (Duhau \& Giglia, 2008)—. También la privatización de espacios otrora públicos tiene efectos en las relaciones sociales, por ejemplo en las formas de interactuar con el otro. Así, los espacios públicos, que antes eran concebidos como de interacción y socialización, hoy se ven asociados más frecuentemente a inseguridad, delincuencia o peligrosidad, lo que redunda en una pérdida de su calidad de bien público (Janoschka \& Glasze, 2003). Al vecino cada vez se le conoce menos, se le ve con suspicacia y cautela, e incluso tienden a debilitarse ciertos sentimientos sociales, como los de 
solidaridad y confianza, rompiéndose así la interacción social tan importante para articular barrios, calles y colonias (Enríquez, 2007).

En el marco descrito, este documento analiza las transformaciones socioespaciales ocurridas en el municipio de Metepec derivadas de la acelerada construcción de urbanizaciones cerradas. Su propósito es detectar cambios en lo físico (las funciones de estas nuevas manifestaciones urbanas) y en lo social (las relaciones entre las personas), de manera que puedan ser proyectados a otros espacios urbanos caracterizados por una alta presencia de urbanizaciones cerradas (Rodríguez, 2007).

El tema de este trabajo es relativamente reciente en la literatura y se inscribe en el interés de explicar la manera en que, producto de la construcción de urbanizaciones cerradas, se inscriben en la ciudad determinadas transformaciones socioespaciales o nuevas formas de habitar y conformar el espacio urbano. Lo nuevo de este tema de estudio implica enfrentar limitantes conceptuales y metodológicas derivadas de la ausencia de estructuras teóricas consolidadas en este aspecto de lo urbano, y a la vez significa avanzar en el conocimiento de las urbanizaciones cerradas con el fin de contribuir a reducir esa debilidad inherente a lo novedoso del tema.

\section{Las urbanizaciones cerradas: aproximaciones}

Para abordar el concepto de "urbanización cerrada", es necesario comenzar distinguiéndola de la manera en que las sociedades tradicionales organizaron y dieron sentido a sus espacios sociales - es decir, lo que algunos antropólogos y sociólogos han denominado "comuna"-, principalmente por romper con la forma convencional de la organización social. No hay que perder de vista que la organización, distribución y sentido de los espacios de las ciudades contemporáneas responden a principios muy distintos de aquellos de la sociedad tradicional y moderna. En primer lugar, porque la forma de organización de la ciudad actual se ha complejizado en cuanto a sus actividades económicas, financieras, culturales, y en la forma de construir los espacios. Ejemplo de tal proceso es el caso de los sistemas de barrios cerrados, los cuales responden a distintos intereses y necesidades dependiendo del sector de la población al que vayan dirigidos. Así, el municipio de Metepec, cercano a la ciudad de Toluca, originalmente era un asentamiento de grupos de población de ingresos bajos, dedicados primordialmente a la agricultura (cultivo de maíz) en pequeña propiedad o propiedad ejidal. Cuando la ley permitió la compraventa de suelo ejidal (1992), los desarrolladores inmobiliarios adquirieron grandes superficies de suelo y edificaron urbanizaciones cerradas para grupos de población de ingresos medio alto y alto, que comenzaban a migrar a la Zona Metropolitana de Toluca debido a su cercanía con la Zona Metropolitana de la Ciudad de México (media hora en automóvil), a su menor nivel de precios (especialmente en materia de suelo, vivienda y educación) y al entorno urbano más seguro.

\section{Algunas definiciones}

En cuanto a la noción misma de "urbanización cerrada", ella ha sido expuesta en diferentes trabajos de investigación que, aplicando diversas denominaciones, destacan en- 
tre sus principales componentes los principios de exclusividad, seguridad y exclusión (véase, por ejemplo, Janoschka \& Glasze, 2003; Roitman, 2004; Duhau \& Giglia, 2004; Blakely \& Gail, 2002). Roitman (2004) las define en la siguiente forma:

En principio, las urbanizaciones cerradas deben ser consideradas como un área residencial cerrada en donde el espacio público ha sido privatizado por la ley, restringiendo el acceso vehicular o peatonal. De esta forma se privatiza el uso de calles, plazas y parques dentro del perímetro de la urbanización. Estos espacios solo pueden ser usados por los residentes, manteniendo a las personas no deseadas fuera del perímetro del conjunto residencial. La urbanización cerrada incluye viviendas unifamiliares de propiedad individual y otros edificios o espacios de uso común que son de propiedad colectiva. Este tipo de desarrollo residencial es concebido desde su inicio como un lugar cerrado y privado y cuenta con una serie de dispositivos de seguridad, como un cierre perimetral (muro, alambrado o rejas), alarmas, cámaras de circuito cerrado y guardias de seguridad. (p. 9)

En algunos casos, los guardias a que hace mención Roitman incluso portan armas de fuego. Y, por lo general, el complejo cuenta con servicios e infraestructura de alta calidad.

Un componente central de estas urbanizaciones es el relacionado con la exclusión. Es decir, no todas las personas pueden ser partícipes del espacio acotado, ni pueden disfrutar de sus beneficios. Los complejos de este tipo se apoyan en una baja concentración de población para la vivienda residencial, y se localizan usualmente fuera del centro urbano (Duhau \& Giglia, 2004). Presentan, además, bardas perimetrales que no solo delimitan el espacio, sino que también son asociadas a la seguridad y tranquilidad que proporcionan a los residentes. Es decir, establecen una marcada separación entre los de adentro y los de afuera. Se trata así de una expresión arquitectónica que instaura la sensación de aislamiento de sus habitantes con respecto a actores sociales ajenos a las edificaciones, los cuales son percibidos como potencialmente peligrosos (por ejemplo, asaltantes, violadores); en esa categoría caen incluso los transeúntes comunes y corrientes, pero no pertenecientes al lugar (López \& Rodríguez, 2005).

Otro elemento más que se presenta en las urbanizaciones cerradas es el de los denominados dispositivos de seguridad que se instalan en los conjuntos mismos, en sus calles privadas y en las viviendas. Tales dispositivos comprenden no solo las bardas perimetrales, que oscilan entre los dos y los cuatro metros de altura, sino también alambres electrificados en las bardas, circuitos cerrados de monitoreo, rejas en puertas y ventanas de las viviendas, vigilancia privada apoyada en ocasiones por perros de ataque, casetas de vigilancia en las entradas de la urbanización, plumas de control y portones automáticos que impiden el libre acceso hacia el interior (Blakely \& Gail, 2002).

Una última característica clave se relaciona con la reglamentación interna y externa que regula las relaciones sociales entre los habitantes de estos conjuntos con relación con el pago de servicios, adecuaciones del inmueble, préstamos o arrendamientos del inmueble, uso de áreas verdes y comunitarias, uso de ascensor y esta- 
cionamientos, entre otros, así como las relaciones que establecen las mesas directivas con los diferentes niveles de gobierno y con otros actores sociales involucrados (García, 2004).

\section{Transformaciones socioespaciales de las urbanizaciones cerradas}

En esencia, las urbanizaciones cerradas vienen a ser un reflejo de las nuevas formas de transformación y utilización del espacio, que inciden en las relaciones sociales. Por tanto, para entender las transformaciones socioespaciales de las urbanizaciones cerradas se considera necesario explorar sus características principales en torno a tres ejes básicos (Thuillier, 2005): i) Transformaciones físicas; ii) Funciones de las urbanizaciones cerradas; y iii) Transformaciones sociales.

En primer lugar, se considera transformaciones físicas aquellas que se ven reflejadas en expresiones arquitectónicas que trastocan y transforman las imágenes urbanas. Estas expresiones están vinculadas al tipo de materiales empleados en las construcciones y a su dimensionamiento, que está en función del nivel socioeconómico de los habitantes (Thuillier, 2005, p. 10). En esta línea, la presencia de urbanizaciones cerradas ha incidido en la homogenización tanto del diseño como de las dimensiones, arquitectura y densidad de construcción de los conjuntos urbanos. El tamaño y la distribución de las casas, así como la ausencia de construcciones en altura, contribuyen a conformar zonas con bajas densidades y mayor comodidad, en donde están perfectamente definidas las superficies mínimas y máximas de construcción. Al interior de las urbanizaciones cerradas se da una coherencia y homogeneidad arquitectónica y paisajística que marca grandes diferencias entre ricos y pobres, entre los de afuera y los de adentro, y cuya característica básica es una contraposición entre la estructura urbana y arquitectónica de las edificaciones externas y la de las urbanizaciones cerradas (Thuillier, 2005).

Esta forma de edificación de la vivienda, la propia de los conjuntos urbanos cerrados, conlleva de manera implícita la fragmentación, el aislamiento y el sentimiento de exclusividad. Se trata de un fenómeno que no es único de los sectores altos de la sociedad, puesto que también se hace presente en los sectores populares y medios cuando deciden cerrar vialidades a todo aquel que resulte extraño o ajeno a las viviendas que se encuentran dentro de determinado espacio. Al cerrar el recinto al tránsito peatonal y automovilístico ajeno y limitarlo al paso de los residentes, se genera una forma distinta de aislamiento. En este sentido, en las ciudades actuales latinoamericanas se puede observar que "el paisaje urbano de la ciudad tiende cada vez más a fragmentarse por fraccionamientos cerrados que crean límites indefinidos e imprecisos. La ciudad se extiende en un modelo insular donde los fragmentos no proporcionan soluciones de continuidad al conjunto, sino que individualizan el espacio" (Enríquez, 2007, p. 128).

En cuanto a las funciones de las urbanizaciones cerradas, en ellas el sentido de algunos elementos estructuradores de los usos de suelo y de la imagen urbana de la ciudad se desdibujan por su inoperancia, producto de la misma dinámica de la 
constitución y fortalecimiento de lo que se ha llamado la "sociedad espectáculo" (Callejón \& Granados, 2004, entre otros). Esta sociedad transforma parte del viejo mobiliario y usos de suelo, prestación de servicios y equipamientos administrativos, dando paso a nuevos espacios más adecuados a las realidades imperantes en la sociedad contemporánea. En esta nueva realidad — como hemos dicho-, el sentido del espacio público cambia. Es decir, lo que tradicionalmente fue entendido como un bien común, adquiere el sentido de espacio exclusivo y excluyente del otro; se sobrerreglamenta lo que antes era, dentro de ciertos límites, de libre uso; e incluso la normatividad impuesta en muchos de los casos violenta los marcos legales nacionales, estatales y municipales (Enríquez, 2007).

El funcionamiento de las urbanizaciones cerradas se encuentra así sumamente cuidado: se norma o reglamenta el tránsito de personas, se permiten o limitan los flujos vehiculares, se fijan límites de velocidad a los vehículos automotores. Para el caso de los habitantes de las viviendas, a menudo está prohibido secar ropa a la vista de los residentes, dejar libres a las mascotas o cortar el césped fuera de los horarios establecidos. La distribución de alumbrado, iluminación, energía eléctrica y servicios básicos opera con amplias innovaciones tecnológicas. Incluso en el interior de las urbanizaciones cerradas se cuenta con gimnasios, casas de cultura, campos de golf, iglesias, boutiques o escuelas, por citar algunos ejemplos, con el propósito de reducir la interacción del interior con el exterior (Thuillier, 2005).

Finalmente, desde el punto de vista de las transformaciones sociales, el fenómeno de las urbanizaciones cerradas ha generado algunos impactos sociales importantes. Hay quienes han calificado a estos espacios como fenómenos benéficos o positivos, o perjudiciales o negativos. Los primeros se relacionan con la creación de puestos de trabajo en el sector de la construcción, en la jardinería y seguridad, además de aquellos relacionados con los servicios que se ofrecen a la nueva población (como servicios de comida y reparto a domicilio). Otro beneficio se relaciona con la dotación de mejores servicios e infraestructura en cuanto a calidad y variedad destinada principalmente a los residentes, pero que también beneficia a la población de las zonas cercanas. Por su parte, los impactos sociales negativos o perjudiciales están vinculados principalmente a cambios en las prácticas sociales (donde el accionar del individuo influye y es influido por la organización social), el establecimiento de relaciones sociales (vinculadas con las preferencias sociales, económicas, políticas y legales relacionadas con el interés y motivación de los propios actores sociales) y el aumento de la segregación social urbana (producto de la limitada interacción de la población de adentro con el resto de la sociedad) derivada de la elección residencial (Roitman, 2004, p. 10).

Según varios autores (Caldeira, 2000; Low, 2000; Cabrales \& Canosa, 2001; Prévot, 2008; Borsdorf \& Hidalgo, 2009; Hidalgo, 2004; entre otros), la principal consecuencia en la esfera social se deriva del comportamiento de los propios actores sociales. Los residentes de las urbanizaciones cerradas generalmente carecen de contacto con los habitantes de los barrios de los alrededores, los cuales suelen estar conformados por grupos de ingresos medios y bajos. Esto incrementa las diferencias entre el afuera y el adentro e influye en las percepciones hacia los "otros". 
Incluso se generan sentimientos de miedo (en el caso de los residentes de las urbanizaciones cerradas hacia el resto), al considerar a los de afuera potencialmente peligrosos; y de resentimiento, envidia o simplemente desinterés (en el caso de los residentes de los alrededores), al observar las diferencias entre el afuera y el adentro.

$\mathrm{El}$ cambio en las relaciones sociales se ve reflejado en un individualismo creciente. El conocimiento respecto del vecino es cada vez más débil, producto en buena medida de los procesos de aislamiento y exclusión que ocurren en algunos de los conjuntos urbanos. Pero también puede generarse aislamiento entre los propios residentes de las urbanizaciones cerradas: en la vida cotidiana o cuando se realizan asambleas, que por lo general son obligatorias, los vínculos entre los residentes suelen ser imperceptibles. En este sentido, se puede apreciar que el sentimiento de solidaridad comienza a tener matices distintos, los cuales reflejan percepciones cada vez más débiles con respecto a la "grupalidad" (Thuillier, 2005, p. 15).

Se ha podido constatar que solo en situaciones en que los intereses individuales son afectados, los individuos de la urbanización cerrada comienzan a volverse al grupo; es decir, se da un proceso en que el individuo se reconoce a sí mismo como parte de un conglomerado mayor y adquiere conciencia de que únicamente en conjunto y en coordinación con el resto del grupo logrará defenderse de quien amenaza sus intereses individuales. De este modo se da inicio a la identificación del yo con respecto al ustedes y a los otros. Es entonces cuando los vecinos y el vecino comienzan a formar parte de y a pensar en el beneficio de la grupalidad. No obstante, incluso bajo estas circunstancias, su actuar sigue siendo más por interés particular que por el del grupo (Enríquez, 2007).

En esta realidad se comienza a constituir lo que se ha denominado la sociedad líqui$d a$, aquella donde las identidades son más fluidas, inestables y menos sólidas, y han de reinterpretarse continuamente (Chambers, 1994). En este sentido, tenemos que concienciarnos respecto de que la pertenencia y la identidad son negociables y revocables, que el problema es "el grado de fluidez identitaria. No es el mismo grado de fluidez del hormigón fresco o la lava, que el del mercurio o el aceite. (...) hay que tener en cuenta que la identidad necesita de una cierta consolidación (...) si se quiere evitar el riesgo de individuos 'fluidos' que, en última instancia, acaben no sintiendo la necesidad de arraigo, pertenencia o compromiso" (Alsina \& Medina, 2006, pp. 130-131).

En esta nueva sociedad se ensayan también nuevas formas de edificación, de estilo arquitectónico, de sentido de las construcciones y, sobre todo, de dinámicas en las que se incrustan las relaciones sociales y la nueva configuración de los espacios, así como su significado (Bauman, 2007). Es en esta nueva connotación de los espacios públicos que se identifican empíricamente las características de las denominadas sociedades líquidas en la realidad del municipio de Metepec.

En estos términos, adquiere relevancia explorar las siguientes preguntas: las nuevas relaciones sociales, ¿generan nuevas configuraciones y significados del espacio? Este postulado de carácter general, ¿se cumple para un municipio altamente urbanizado como Metepec? ¿Con qué intensidad? ¿Cuáles serían sus singularidades locales? Justamente estas preguntas se exploran en el estudio de caso que articula este documento. 


\section{Diseño metodológico de la investigación}

El desarrollo metodológico de la investigación contempla los siguientes elementos: localización, población analizada, muestra estadística, recopilación de datos y cartografía oficiales, trabajo de campo, análisis, interpretación y presentación de resultados. Las técnicas de recolección de información utilizadas fueron la observación directa, la revisión sistemática de información y la representación cartográfica (Janoschka, 2002).

El carácter de la presente investigación es cualitativo (Salgado, 2007). En ese sentido, la encuesta aplicada no tiene como propósito producir generalizaciones estadísticas. La información con que se sustenta la argumentación en torno al fenómeno en estudio destaca variables extraídas al instrumentar técnicas de investigación como la observación directa de las urbanizaciones cerradas en el municipio de Metepec y entrevistas semiestructuradas a informantes clave (Sampieri, 2002). Se consideraron informantes clave los residentes de urbanizaciones cerradas y vigilantes.

Con la técnica de la observación directa se obtuvo información relacionada con variables e indicadores de confinamiento, principalmente dispositivos de seguridad como bardas perimetrales, casetas de vigilancia, cercas electrificadas, plumas que limitan el acceso hacia los conjuntos urbanos, cámaras de video, perros de ataque, rejas, entre otros (Figura 1).

FIgURA 1 | Dispositivos de seguridad en urbanizaciones cerradas: Los Álamos y Rincón Viejo. Metepec, México
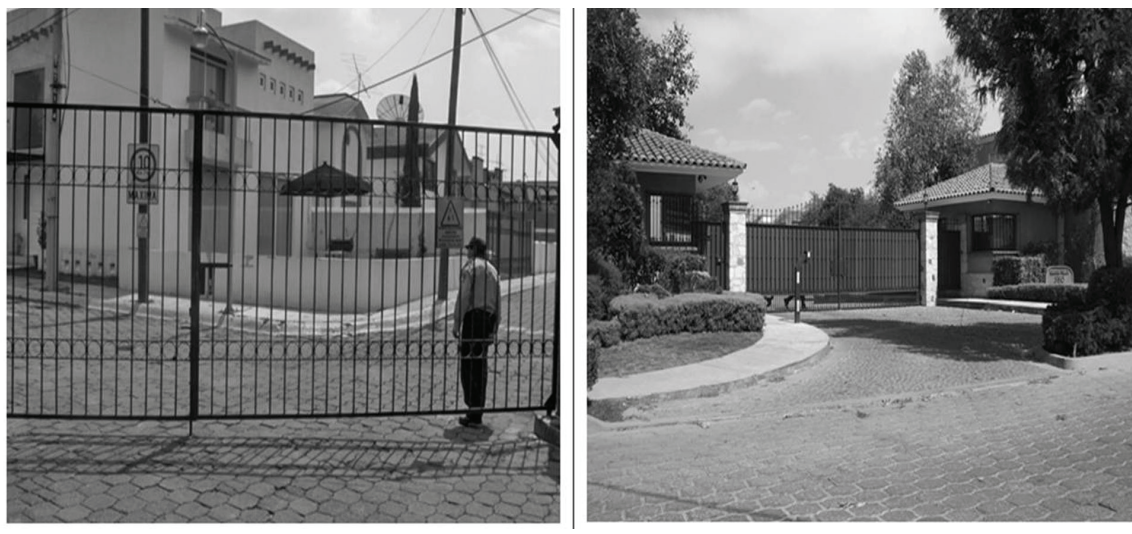

FUENTE ARCHIVO PROPIO, 2011

Al mismo tiempo, se detectó cómo las urbanizaciones cerradas constituyen una nueva imagen urbana cargada de expresiones y simbolismos de exclusión. Este modelo de ocupación del espacio incide por contagio en la transformación de viviendas construidas y en construcción de las áreas circundantes, que toman como modelo las características de la vivienda de conjuntos urbanos cerrados. Prueba de 
esto es la existencia de calles en los alrededores de urbanizaciones cerradas que han sido aisladas, dándoseles un carácter privado y limitando el acceso mediante plumas, jardineras, rejas o casetas de vigilancia construidas sobre las veredas.

FIGURA 2 | Privatización de calles: Residencial Amphitrite

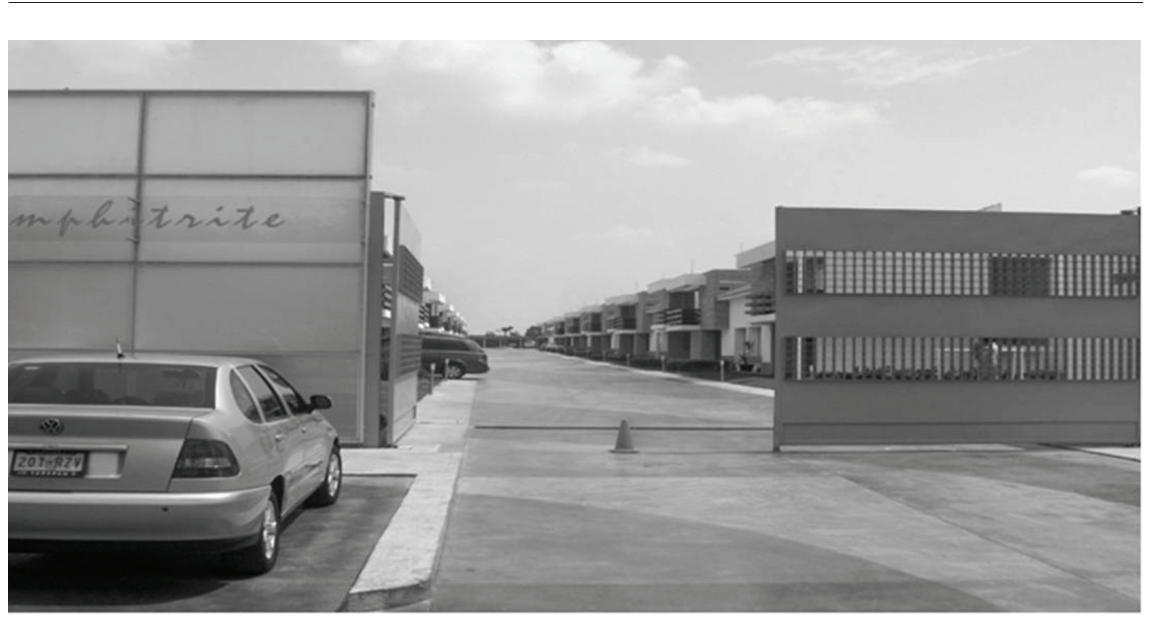

FUENTE ARCHIVO PROPIO, 2011.

Para comprender algunos cambios sociales dentro de las urbanizaciones cerradas se llevaron a cabo entrevistas semiestructuradas ${ }^{1}$ a residentes y vigilantes de las urbanizaciones cerradas (Sampieri, 2002). En total se aplicaron cincuenta cuestionarios de manera aleatoria a residentes de las siguientes urbanizaciones cerradas: Las Buganvilias, Fraccionamiento Residencial San Ángel, Residencial El Encino y Residencial San Marino. Para el caso de los vigilantes de las urbanizaciones cerradas, por medio de las entrevistas semiestructuradas (Salgado, 2007) se buscó rescatar su conocimiento respecto del trabajo que desempeñan y la percepción que tienen del tipo de relaciones sociales que establecen los residentes de las urbanizaciones cerradas. Al mismo tiempo se identificó, desde la visión de estos actores, la presencia de sentimientos como inseguridad, exclusividad, exclusión y algunas de las razones que los motivan.

Cabe aclarar que, en el caso de algunas urbanizaciones cerradas, resulta prácticamente imposible establecer contacto con sus residentes en sus viviendas, debido a las fuertes restricciones de acceso. Por ello se decidió entrevistar a residentes de conjuntos urbanos residenciales con el apoyo de amistades y conocidos, por los cuales se facilitó el contacto. No obstante, incluso con este apoyo, el proceso comenzó a tornarse lento y tortuoso, con avances por debajo de los esperados. De ahí que se

1 Se entiende como entrevista semiestructurada la charla entre dos o más sujetos en la cual se sigue un guion ya establecido. Para el caso de este trabajo, se conversó en torno a temas relativos a la inseguridad, el sentimiento de miedo, exclusividad y exclusión. 
optara por la estrategia de abordar a los actores referidos en algunos puntos de reunión a los que ellos acostumbran acudir para desarrollar actividades ya sea deportivas, de esparcimiento o de interacción social. Este fue el caso del Club Campestre San Carlos. Para instrumentar tal estrategia se recurrió nuevamente a contactos conocidos, esta vez algunos que tienen la calidad de socios de dicha institución, lo que facilitó los trámites administrativos para ingresar a ella y el contacto en un solo espacio con habitantes de distintos conjuntos cerrados de Metepec. Con ello se logró finalmente reducir el tiempo de trabajo dedicado a las entrevistas.

El escenario descrito permitió llevar a cabo algunas entrevistas a grupos de mujeres de una edad promedio de treinta a cuarenta años, en su mayoría dedicadas a actividades profesionales. Las entrevistas fueron aplicadas en la cafetería del club, en horario matutino, antes de que dieran inicio a sus actividades cotidianas. Los grupos que se llegaron a constituir oscilaban entre tres y cuatro integrantes. Se entrevistó principalmente a mujeres porque los contactos que facilitaron el ingreso fueron femeninos y la mayoría mantenía mayor relación con personas de su mismo género. Al final se lograron cinco encuentros con este tipo de grupos de mujeres.

La información generada en estas entrevistas permitió rescatar datos que facilitaron la comprensión del fenómeno de la urbanización cerrada. Asimismo, hizo posible entender los cambios que ha provocado este tipo de construcciones, no solo en la redefinición del espacio y su imagen urbana, sino también en el nuevo sentido que adquieren sentimientos como el de exclusividad, exclusión, inseguridad, solidaridad y/o reciprocidad entre los residentes.

Para codificar las variables referidas a la hora de interpretar las respuestas proporcionadas en las entrevistas, así como en los cuestionarios aplicados, se asignó un número ascendente a las variables de mayor relevancia para esta investigación. A la variable Inseguridad se le asignó el número 1, a Exclusividad el número 2, el 3 a Exclusión y el número 4 a Otros. Luego, cada una de estas variables fue cuantificada por el número de veces enunciadas en el total de cuestionarios y entrevistas. Con base en esta cuantificación pudo ser posible identificar de manera jerárquica algunas de las razones por las que los residentes optan por habitar en conjuntos cerrados. Este método se tomó de las formas de medición desarrolladas por trabajos de carácter antropológico, específicamente de la bitácora de campo, la cual fue adaptada para esta investigación.

\section{Transformaciones socioespaciales en Metepec, México, 1990-2010}

\section{Zona de estudio}

El Área Metropolitana de Toluca (AMT) se localiza a media hora de la Ciudad de México (40 kilómetros en dirección suroeste) y forma parte de la Zona Metropolitana de Toluca, que está integrada por doce municipios del Estado de México. Tiene una superficie de 269,6 kilómetros cuadrados: su eje de longitud máxima este-oeste es de 31,6 kilómetros y el norte-sur es de 21,1 kilómetros. Con 1,8 millones de habitantes, es una de las cinco ciudades más grandes del país. El empleo formal, por su parte, 
ha tenido un comportamiento ascendente, aunque afectado por las recurrentes crisis económicas del país: en 1994 contaba con 157.284 empleos, que llegaron a 267.603 en 2004, lo que indica que, más allá de coyunturas económicas, Toluca es una de las ciudades más dinámicas del país y ha enfrentado un crecimiento metropolitano de gran escala. Esto ha modificado su estructura urbana y ha transformado la ciudad monocéntrica de principios de la década de los ochenta en una enorme área metropolitana policéntrica al inicio del siglo veintiuno (Garrocho \& Campos, 2009).

Uno de los doce municipios que integran la Zona Metropolitana de Toluca es Metepec, que se localiza a treinta minutos en automóvil de la Ciudad de México en dirección suroeste. Metepec alcanza 70,85 kilómetros cuadrados de extensión territorial y es considerado uno de los municipios con mayor fortaleza económica, más alto índice de calidad de vida y con mayores niveles de seguridad del país (Plan de Desarrollo Municipal de Metepec 2006-2009).

FIGURA 3 | Plano de localización

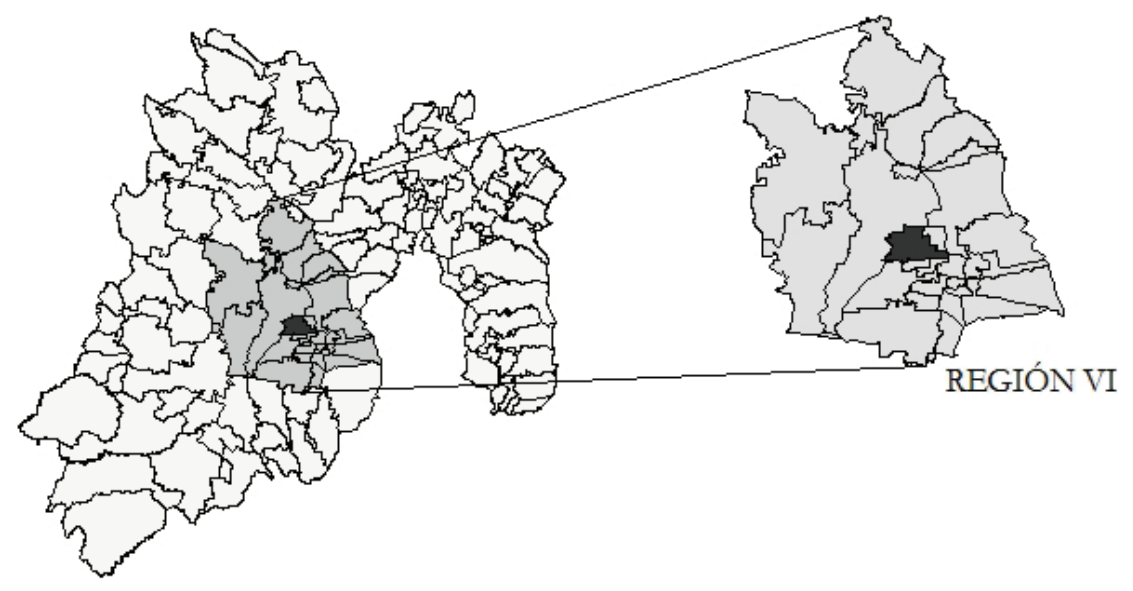

fuente elaboración propia con base en el Plan de Desarrollo del H. Ayuntamiento de Metepec, 2009 2012.

En el periodo de estudio referido, el municipio de Metepec ha sido objeto de fuertes inversiones en actividades comerciales, de servicios y en la construcción de vivienda residencial media y alta, situación que derivó en transformaciones físicas significativas de la imagen urbana, producto de la adopción de nuevos estilos arquitectónicos para el caso de las viviendas. Por otro lado, las actividades comerciales 
y de servicios recibieron grandes extensiones de suelo urbano destinadas a la construcción de centros que las acogieran, y también de plazas, ambos tipos de espacios con el carácter de urbanizaciones cerradas.

Si la nueva forma de organizar el espacio urbano trajo consigo también formas nuevas de relaciones sociales, manifiestas - en el caso de las viviendas- en la notoria exclusión y exclusividad a que nos hemos referido, ello también es aplicable a los nuevos centros comerciales y de servicios: estos constituyen nuevas formas de consumo, que rompen con las formas de consumo tradicional.

\section{Crecimiento demográfico y su relación con la vivienda}

En 1990, Metepec contaba con una población de 140.268 habitantes y un total de 28.546 viviendas; para el año 2000, su población se incrementó a 194.463 habitantes, y a 43.852 viviendas; y hacia 2010 contaba con 214.162 habitantes y 54.914 viviendas (véase INEGI, 1990, 2000 y 2010, respectivamente).

Las profundas transformaciones que ha venido experimentando Metepec, rastreables desde hace aproximadamente veinticinco años, son más notorias en la actividad productiva (dominada por actividades terciarias de alta calidad: edificios de oficinas, grandes centros y plazas comerciales y de servicios), el incremento poblacional y del número de viviendas y un acelerado proceso de urbanización. En menos de veinte años, Metepec transitó de ser un municipio prácticamente rural a uno altamente urbanizado, consolidando en su territorio usos de suelo comercial y habitacional de tipo residencial.

La construcción de vivienda cerrada en Metepec ocurre en distintos momentos. Entre las primeras construcciones de este tipo, que respondieron más al sentimiento de exclusividad que las actuales, se ubican San Carlos (1971) y La Asunción (1980). Luego, de 1990 a 2010, la construcción de vivienda cerrada se desplegó con gran intensidad, debido al éxito de ese modelo para los desarrolladores inmobiliarios, paralelo a la existencia de mayores mecanismos de financiamiento para sectores medios. En ese lapso se detectan algunas innovaciones en el equipamiento de las urbanizaciones, ligadas al mercado al que estén dirigidas. Por ejemplo, algunas ofrecen como principal ventaja la seguridad y privacidad, mientras otras añaden elementos aspiracionales vinculados a nuevos estilos de vida: campo de golf, iglesia, cafeterías, restaurantes, gimnasios, spa, entre otros (i.e. San Carlos, Los Encinos).

Con las nuevas edificaciones se constituyó y consolidó otra forma de hacer ciudad en Metepec y en la Zona Metropolitana de Toluca. ${ }^{2}$ Esto se pudo constatar

2 A pesar de que algunos estudiosos han afirmado que la urbanización cerrada responde más a la des-socialización de la ciudad, por no garantizar el derecho a la ciudad para todos, esto no significa que se deje de hacer ciudad, al igual que se transitó de la ciudad antigua a la ciudad feudal, y de esta a la capitalista, y así sucesivamente. Bajo esta lógica se puede deducir que las ciudades actuales están transitando a otra forma de hacer ciudad con la incorporación de este tipo de construcciones. Por ello, se considera necesario tomar en cuenta el mismo proceso evolutivo de las ciudades y las nuevas formas de entender sus espacios, como el espacio público, que adquieren nuevos significados dependiendo de cómo se constituyan las nuevas realidades. Es el caso de un edificio compuesto por un conjunto de departamentos donde los residentes pueden concebir al ascensor como el único espacio público en el que se socializa y se lleva a cabo la relación cara a cara, al carecer de áreas de esparcimiento y recreación. 
en Metepec con la presencia de distintos espacios urbanos que presentan características de encerramiento. Entre ellos, tres grandes plazas comerciales - Plaza Las Américas, Pabellón Metepec y Galerías Metepec-, además de otros centros comerciales, así como los 115 conjuntos urbanos destinados a la vivienda.

\section{Principales características de las urbanizaciones cerradas de Metepec: la visión de los vigilantes}

Como hemos visto, en Metepec las urbanizaciones cerradas se caracterizan por la presencia de dispositivos de seguridad y la privatización de espacios que tradicionalmente fueron entendidos como bienes públicos, como la calle, los jardines y parques, entre otros (Roitman, 2004). El trabajo de campo realizado en algunas urbanizaciones cerradas de Metepec mostró que son espacios hiperreglamentados en su interior, y que esa reglamentación incide en la forma de relacionar el adentro con el afuera (el entorno social y urbano). Sin duda, las reglas más visibles son las que imponen marcadas restricciones para ingresar al interior de las urbanizaciones cerradas. Así, además de las altas bardas perimetrales, el personal de las casetas de vigilancia se encarga de hacer cumplir ciertas normas a todos, sea que formen o no formen parte del conjunto habitacional. De acuerdo con las entrevistas a vigilantes, a los visitantes se les somete a un proceso de seguridad para autorizar su ingreso. Por lo general, este proceso se inicia con la solicitud de una credencial oficial, aunque también se está generalizando la práctica de fotografiar a los visitantes de frente y de perfil. En ocasiones, el visitante es escoltado por alguna patrulla privada hasta el lugar de destino. Las casetas de vigilancia se convierten cada vez más en un elemento clave en la estructura de los conjuntos urbanos, por lo que son ya elementos constitutivos del nuevo paisaje urbano de Metepec.

Los vigilantes informaron que, además de la identificación oficial que se exige a los visitantes, deben registrarse en un formato que incluye nombre completo, fecha, hora de entrada y salida, así como el nombre de la familia que se visita y el propósito de la visita. Los vigilantes explican que, como política de las empresas de vigilancia, al medio día rotan de puesto con otros integrantes de la guardia para evitar que los centinelas pierdan el interés en la actividad que realizan. Al preguntarles sobre el equipo de seguridad que manejan, respondieron que la empresa solo les proporciona tolete - un instrumento para asestar golpes como los que porta la policía- y gas en aerosol, y que solamente en casos extremos los residentes de los conjuntos les facilitan armas de fuego, las cuales pocas veces son utilizadas.

\section{Metepec y sus urbanizaciones cerradas}

Los condominios y conjuntos urbanos que fueron identificados en el estudio se muestran en el Cuadro 1 y la Figura 4 (esta figura muestra la localización y extensión precisa de cada urbanización cerrada), basados en información oficial del municipio de Metepec. 
CUADRo 1 | Urbanizaciones cerradas en Metepec, México (1990-2011)

\begin{tabular}{|c|c|c|c|c|}
\hline No. & NOMBRE & $\begin{array}{c}\mathrm{N}^{\circ}{ }^{\circ} \mathrm{DE} \\
\text { VIVIENDAS }\end{array}$ & SUPERFICIE & $\begin{array}{l}\text { FECHA DE } \\
\text { CREACIÓN }\end{array}$ \\
\hline 1 & Residencial San Miguel & 4 & $1.216,25$ & 05 -oct-01 \\
\hline 2 & Residencial San Marino & N/D & N/D & N/D \\
\hline 3 & Rinconada San Isidro & 45 & $\mathrm{~N} / \mathrm{D}$ & jul-93 \\
\hline 4 & Fraccionamiento Residencial San Carlos & 320 & $57.000,00$ & 1971 \\
\hline 5 & Villa Margarita & $\mathrm{N} / \mathrm{D}$ & $\mathrm{N} / \mathrm{D}$ & $\mathrm{N} / \mathrm{D}$ \\
\hline 6 & Real Metepec I & 10 & $2.866,88$ & 07 -may-07 \\
\hline 7 & Real Metepec II & 20 & $6.254,74$ & 07 -may-07 \\
\hline 8 & Residencial Casa de las Fuentes & 60 & $24.446,58$ & 07-mar-07 \\
\hline 9 & Real de Azaleas (Quinta las Azaleas) & 37 & $7.317,80$ & 16-dic-07 \\
\hline 10 & Rinconada Tizatlati II & 11 & $5.024,10$ & 10 -abr- 07 \\
\hline 11 & La Concordia Condominio & 60 & $19.423,65$ & 27 -sep-07 \\
\hline 12 & Árboles II & 7 & $1.711,75$ & 06-sep-07 \\
\hline 13 & La Joya Diamante & $\mathrm{N} / \mathrm{D}$ & $24.581,31$ & 26-abr-07 \\
\hline 14 & Villas Dante & $\mathrm{N} / \mathrm{D}$ & $\mathrm{N} / \mathrm{D}$ & $\mathrm{N} / \mathrm{D}$ \\
\hline 15 & Renacimiento & 46 & $9.468,85$ & 11-feb-91 \\
\hline 16 & Casa Magna & 12 & $5.403,33$ & 15 -jun-94 \\
\hline 17 & Fraccionamiento Residencial Villas de Metepec III & 32 & $4.529,15$ & 06-oct-94 \\
\hline 18 & Villas Metepec II & 10 & $3.428,64$ & 06-oct-94 \\
\hline 19 & La Joya Residencial & 43 & $14.319,00$ & 18-ago-91 \\
\hline 20 & Fraccionamiento Residencial Country Club & $\mathrm{N} / \mathrm{D}$ & $\mathrm{N} / \mathrm{D}$ & $\mathrm{N} / \mathrm{D}$ \\
\hline 21 & Fraccionamiento Residencial Fortanet & $\mathrm{N} / \mathrm{D}$ & $\mathrm{N} / \mathrm{D}$ & N/D \\
\hline 22 & Fraccionamiento Residencial Real de Arcos & $\mathrm{N} / \mathrm{D}$ & $\mathrm{N} / \mathrm{D}$ & $\mathrm{N} / \mathrm{D}$ \\
\hline 23 & Olivar del Prado & 20 & $5.326,60$ & 29-may-06 \\
\hline 24 & Residencial Veranda & 43 & $3.214,03$ & $\mathrm{~N} / \mathrm{D}$ \\
\hline 25 & Fraccionamiento Residencial las Haciendas & $\mathrm{N} / \mathrm{D}$ & $\mathrm{N} / \mathrm{D}$ & $\mathrm{N} / \mathrm{D}$ \\
\hline 26 & Rinconada la Isla & 45 & $15.222,42$ & 18 -ene-06 \\
\hline 27 & Monte Llano & 10 & $4.457,40$ & 02 -oct-06 \\
\hline 28 & Residencial la Herradura & 39 & $13.637,10$ & 08-mar-06 \\
\hline 29 & Loma Real & $\mathrm{N} / \mathrm{D}$ & $1.020,36$ & 14-dic-05 \\
\hline 30 & Fraccionamiento Residencial los Murillos & 8 & $2.708,17$ & 15 -feb-00 \\
\hline 31 & Fraccionamiento Residencial San Ángel & 7 & $2.316,65$ & 01-ago-00 \\
\hline 32 & Residencial Villa de Chapultepec & 56 & $5.920,23$ & 27 -abr- 00 \\
\hline 33 & Fraccionamiento Residencial Santa Teresa & 15 & $5.709,23$ & $27-\mathrm{mar}-06$ \\
\hline 34 & Fraccionamiento Residencial Virreyes & $\mathrm{N} / \mathrm{D}$ & $\mathrm{N} / \mathrm{D}$ & $\mathrm{N} / \mathrm{D}$ \\
\hline 35 & Las Bugambilias & N/D & N/D & N/D \\
\hline 36 & Del Virrey & 81 & $9.200,00$ & 1990 \\
\hline 36 & Residencial Campestre del Virrey & $\mathrm{N} / \mathrm{D}$ & $91.785,26$ & 14-jun- 05 \\
\hline 37 & Azaleas & 22 & $4.695,19$ & 2003 \\
\hline 38 & Residencial Coapa I & 10 & $2.977,97$ & 21-nov-06 \\
\hline 39 & Residencial El Manantial & 60 & $19.375,00$ & 10 -jul-06 \\
\hline 40 & El Baldaquín 2 & 53 & $18.285,54$ & 08-mar-06 \\
\hline 41 & Valle Linda & 20 & $6.112,00$ & 09-ene-06 \\
\hline 42 & Los Almendros & 43 & $17.778,85$ & 2006 \\
\hline 43 & Residencial Vallarta & 8 & $2.764,15$ & $15-$ feb-06 \\
\hline 44 & Residencial El Encino & N/D & N/D & N/D \\
\hline 45 & Rinconada Tizatlati & 15 & $5.920,23$ & 06-mar-06 \\
\hline 46 & Residencial Amphitrite & 28 & $9.473,46$ & 14-sep-06 \\
\hline 47 & Las Jaras & 56 & $12.381,67$ & 13 -ene- 05 \\
\hline 48 & Bosques de Sauces & 19 & $5.709,40$ & 23-mar-06 \\
\hline 49 & Villa Romana II & 60 & $21.234,00$ & 26-ene- 06 \\
\hline 50 & Bosque de Ciruelos & 43 & $14.319,06$ & 18 -ago- 05 \\
\hline 51 & El Gran Roble & N/D & $\mathrm{N} / \mathrm{D}$ & $\mathrm{N} / \mathrm{D}$ \\
\hline 52 & Villas Margarita & 17 & $4.917,40$ & 15-nov-05 \\
\hline 53 & Residencial Tres Robles & 29 & $14.038,19$ & 01-feb-05 \\
\hline 54 & Fraccionamiento Residencial las Américas & 149 & $18.553,00$ & 24 -jul-92 \\
\hline 55 & Maple Residencial & 8 & $2.006,77$ & 14 -jun- 05 \\
\hline 56 & Villas San Román & 8 & $2.409,34$ & 08-jun-04 \\
\hline 57 & La Gavia Residencial & 42 & $14.062,00$ & 18-jun-01 \\
\hline 58 & Residencial La Asunción & 6 & $2.400,00$ & $27-a b r-04$ \\
\hline
\end{tabular}




\begin{tabular}{|c|c|c|c|c|}
\hline 59 & Residencial San Rafael & 20 & $9.909,27$ & 10 -dic- 03 \\
\hline 60 & Santa Cecilia III & 18 & $8.524,96$ & 14-oct- 03 \\
\hline 61 & Santa Cecilia II & 25 & $11.868,37$ & 05-jun-03 \\
\hline 62 & La Alondra & 12 & $2.490,21$ & 22 -abr-03 \\
\hline 63 & Rancho las Palomas & 50 & $14.614,01$ & 04-jun-03 \\
\hline 64 & Villas del Sol & 15 & $4.857,00$ & 05-jun-03 \\
\hline 65 & Villa los Arrayanes & 13 & $3.276,65$ & 30-jun-03 \\
\hline 66 & Campestre del Valle & 41 & $10.247,59$ & 07 -oct- 02 \\
\hline 67 & Residencial Galápagos I & 17 & $3.791,13$ & 03 -oct- 02 \\
\hline 68 & Residencial Verona & 40 & $12.045,00$ & 16 -ene-02 \\
\hline 69 & Residencial Vessal & 46 & $13.190,33$ & 18-oct- 01 \\
\hline 70 & San Antonio Regla & 14 & $33.845,12$ & oct-01 \\
\hline 71 & Residencial Teo & 4 & $1.499,89$ & 05 -oct- 01 \\
\hline 72 & Los Alcatraces & 14 & $33.845,12$ & 15 -oct- 01 \\
\hline 73 & Rincón Viejo & 25 & $12.580,75$ & 19-ago-01 \\
\hline 74 & Residencial San Luis & 10 & $5.677,50$ & 03-ago-01 \\
\hline 75 & Rinconada Mexicana & 29 & $7.971,45$ & 08-nov-01 \\
\hline 76 & La Agavia I & 39 & $9.145,51$ & 30 -jul-04 \\
\hline 77 & La Capilla Residencial & 6 & $1.4198,26$ & 30 -abr-01 \\
\hline 78 & Villas Country & 25 & $10.732,12$ & 22-oct-01 \\
\hline 79 & Los Agaves & 10 & $3.400,57$ & 17 -dic-99 \\
\hline 80 & Las Magnolias & 18 & $6.829,00$ & 14-sep-97 \\
\hline 81 & Los Sauces & 25 & $4.722,75$ & 08-ago-97 \\
\hline 82 & San Miguel & 57 & $26.962,68$ & 21-ene-97 \\
\hline 83 & Conjunto Residencial Le Blanc & 17 & $8.170,78$ & $27-$ mar-97 \\
\hline 84 & Los Reyes & 13 & $4.748,70$ & 04-sep-96 \\
\hline 85 & Condominio Metepec & 24 & $10.000,00$ & 08-mar-94 \\
\hline 86 & Villas Dulce & 7 & $4.541,00$ & 03 -oct-94 \\
\hline 87 & El Pueblito I y II & 15 & $4.419,22$ & 07 -oct-94 \\
\hline 88 & San Agustín & 15 & $2.459,44$ & 11-mar-93 \\
\hline 89 & Villas Estefanía & 54 & $12.902,67$ & sep-93 \\
\hline 90 & Residencial Candilejas & 56 & $11.900,00$ & 15 -feb-93 \\
\hline 91 & El Campanario & 48 & $14.760,70$ & mar-91 \\
\hline 92 & Condominio del Solar & 6 & $1.360,00$ & 06-ago-93 \\
\hline 93 & Residencial Vitrales de Metepec & 60 & $12.457,51$ & 08-ene- 93 \\
\hline 94 & Tres Garantías & 19 & $3.721,18$ & 22-mar-93 \\
\hline 95 & Las Mitras & 42 & $12.055,21$ & $25-\mathrm{feb}-93$ \\
\hline 96 & Conjunto Victoria & N/D & $2.329,50$ & 08-dic-93 \\
\hline 97 & Real de San Jerónimo & 53 & $12.652,95$ & feb-93 \\
\hline 98 & Quinta las Manzanas & 57 & $20.901,88$ & 29-jun-93 \\
\hline 99 & Fraccionamiento Residencial Real de Arcos & 26 & $7.911,19$ & 29-ago-01 \\
\hline 99 & Los Arcos I y II & 6 & $1.961,61$ & jul-93 \\
\hline 100 & Residencial Balmoral & 83 & $\mathrm{~N} / \mathrm{D}$ & 1993 \\
\hline 101 & Residencial las Glorias & 52 & $16.069,40$ & sep-92 \\
\hline 102 & Residencial Los Santos & 17 & $4.186,00$ & mar-92 \\
\hline 103 & Villa Dorada & 35 & $108.887,10$ & 08 -oct-91 \\
\hline 104 & Conjunto Residencial Villas Alteza & 60 & $12.478,37$ & 19-dic-91 \\
\hline 105 & Fraccionamiento Residencial Santa Teresa & $\mathrm{N} / \mathrm{D}$ & $\mathrm{N} / \mathrm{D}$ & N/D \\
\hline 105 & Villas Santa Teresa & 28 & $3.768,46$ & 21-nov-91 \\
\hline 106 & Residencial Matamoros & 9 & $1.211,35$ & 10-may-91 \\
\hline 107 & Residencial Altamirano & 9 & $2.459,00$ & may-90 \\
\hline 108 & Puerta de Hierro & 51 & $16.126,79$ & 1990 \\
\hline 109 & Lomas de San Isidro & 58 & $11.681,00$ & 14 -feb-90 \\
\hline 110 & Los Álamos & 14 & $4.134,27$ & 1990 \\
\hline 111 & Conjunto Fortanet & 12 & $5.110,64$ & 1990 \\
\hline 112 & El Carmen & 9 & $3.582,50$ & 1990 \\
\hline 115 & Las Haciendas & N/D & N/D & N/D \\
\hline
\end{tabular}

FUENTE ELABORACIÓN PROPIA CON BASE EN LOS EXPEDIENTES DE LOS INVENTARIOS DE LOS CONJUNTOS HABITAcionales de Secretaría de Desarrollo Urbano, Registro Estatal de Desarrollo Urbano y la Dirección de Desarrollo Urbano y Obras Públicas del municipio de Meterec, 2008.

Actualizado mediante trabajo de campo en 2011.

NOTA Se tomó en consideración el Fraccionamiento Residencial San Carlos como parte de la muestra a pesar de haber sido construido en 1971, por reunir en su Club Deportivo una parte considerable de informantes clave de diferentes condominios horizontales pertenecientes a Metepec, Estado de México, que brindaron información de interés para la investigación. N/D No disponible. 


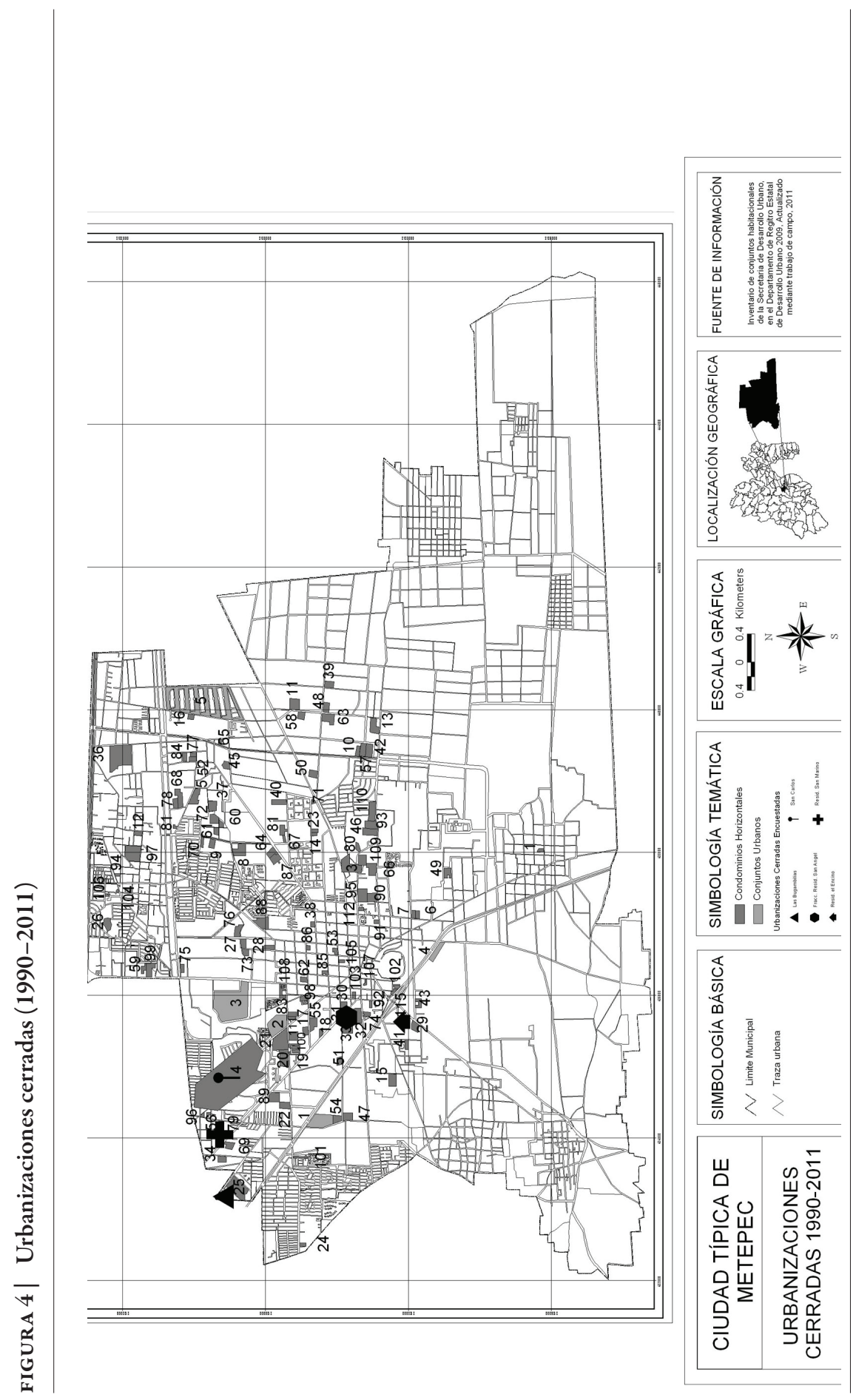


En Metepec se pudo constatar la presencia de edificaciones cerradas de distintas denominaciones, tales como condominios horizontales y conjuntos urbanos, construidos desde la década de los noventa hasta la actualidad, y que por lo general están orientados a grupos de ingreso medio y alto (Roitman, 2004; Rodríguez, 2004).

De acuerdo con el Plan de Desarrollo Urbano 2009-2012 de Metepec, los conjuntos urbanos han sido los que han reportado una mayor oferta de vivienda en los últimos veinte años. Esto explica la imagen urbana del municipio, un espacio territorial caracterizado por edificaciones "exclusivas" — esto es, excluyentes—, que a la vez reflejan y producen un patrón de relaciones sociales también excluyentes tanto hacia el interior de los conjuntos urbanos como hacia el exterior. Más aún, los elementos físicos de exclusión no solo han sido incorporados a las edificaciones destinadas a la vivienda, sino que también forman parte fundamental de las construcciones comerciales y de las dedicadas a la prestación de servicios, graficando así claramente las transformaciones de las relaciones sociales, asociadas a estos espacios urbanos.

\section{Redefinición de las relaciones sociales: la visión de las residentes}

Del trabajo empírico se pudo constatar que la totalidad de las residentes entrevistadas ${ }^{3}$ prefiere habitar en urbanizaciones cerradas antes que en viviendas tradicionales que se localizan en espacios abiertos. Del total de las entrevistadas, alrededor del $60 \%$ decidió optar por urbanizaciones cerradas por la exclusividad y la seguridad que proporcionan; al $40 \%$ ya no le resulta relevante constituir vínculos sociales entre sus vecinos; y alrededor de 55\% respondió no conocer a la mayoría de sus vecinos, lo cual deriva en una creciente apatía para pensar en la grupalidad y en un protagonismo de su individualidad.

Las entrevistas permitieron constatar, así, que los habitantes de estos espacios cerrados difícilmente establecen vínculos estrechos con sus vecinos. Las principales razones aducidas son la desconfianza y el desconocimiento total o parcial de quien habita las viviendas adjuntas. Solo en situaciones especiales, como reuniones vecinales que se realizan periódicamente para analizar la situación de la urbanización, se socializa sobre ciertos problemas comunes. Esto en el caso de que los vecinos asistan a dichas reuniones, lo que no siempre sucede.

Lo anterior, aun siendo generalizado, no ocurre en todas las urbanizaciones cerradas. Se encontraron casos en que el conocimiento mutuo entre los vecinos es muy significativo y se deriva en buena medida de las dinámicas de funcionamiento de las mesas directivas de los conjuntos. Es decir, las mesas directivas y las reuniones de vecinos para tratar problemas comunes constituyen estructuras vecinales que han permitido no solo solucionar problemas y satisfacer demandas, sino impulsar la socialización y construcción de vínculos entre los residentes de las urbanizaciones cerradas. Las actividades que incentivan la cercanía y cooperación de los residentes están vinculadas principalmente a problemas de las urbanizaciones cerradas que se analizan en reuniones periódicas, así como al desarrollo de actividades de beneficio

Para el caso de las entrevistas realizadas, los informantes solicitaron, en su mayoría, no se mencionara su nombre. 
común. Cabe mencionar que esto se ha apoyado en reglamentos coercitivos que regulan gran parte de la interrelación, más que en la importancia del trato cotidiano o la realización de eventos sociales entre vecinos. Así, solo el 20\% de las residentes entrevistadas manifestó desarrollar acciones que estrechan los vínculos y conocimiento de los habitantes de sus respectivos espacios cerrados.

Por otra parte, de veinte entrevistas aplicadas, trece informantes coincidieron en que algo que obstaculiza el fortalecimiento de vínculos entre los residentes es la constante circulación de quienes habitan las viviendas, porque alrededor del $45 \%$ de ellos no son propietarios, sino que las rentan por un tiempo y después desaparecen. Este fenómeno es un freno al desarrollo de relaciones interpersonales, situación a la que contribuye el hecho de que muchos de los habitantes prácticamente no se encuentran durante el día en sus viviendas. De acuerdo con los entrevistados, alrededor del 35\%, entre propietarios y arrendatarios, trabaja en la Ciudad de México, y solo se los detecta por la noche, cuando encienden la iluminación de sus hogares.

Seis de las informantes afirman que solo cuando se han presentado problemas que afectan a los residentes se ha buscado la interacción. Esto se puede ejemplificar de manera adecuada con el caso de la urbanización cerrada Rancho La Virgen (de ingreso medio alto y alto). Según algunas de sus residentes, ante la iniciativa del gobierno estatal de urbanizar terrenos muy extensos de reserva forestal asignados a la Secretaría de Desarrollo Agropecuario, los residentes de la urbanización iniciaron un movimiento de protesta que detonó una dinámica muy intensa de conocimiento y reconocimiento entre ellos, lo que generó otro tipo de relación, mucho más personal, que la que venían desarrollando en el pasado cotidiano. Así aglutinados, los residentes no solo evitaron que se urbanizaran los terrenos forestales, lo que implicaba derribar miles de árboles, sino que, con su movimiento, lograron que el gobierno del estado construyera un parque metropolitano, denominado Parque Bicentenario, que se convirtió en uno de los más importantes de la Zona Metropolitana de Toluca.

Otro dato interesante que se desprende de las entrevistas es que la reglamentación existente en estos espacios cerrados también incide en el comportamiento de los habitantes. Es muy común que las mesas directivas de los conjuntos urbanos tomen decisiones sin ser aprobadas por la mayoría de los residentes, y quien no cumple con la normativa así establecida, ${ }^{4}$ simplemente se ve excluido de todo lo que compete a los problemas colectivos. En muchos casos, quien no coopera con el grupo debe enfrentar a solas diversos problemas propios del conjunto cerrado.

Esta situación también se refleja hacia el exterior de los conjuntos urbanos cerrados, debido a que las bardas son excluyentes del otro, principalmente de lo que había sido considerado como espacios públicos. Esto se aprecia en el cierre y privatización de calles. Para el caso de los conjuntos cerrados, la privatización de la calle es justificada por los propietarios, que aducen que el dueño del terreno es quien

4 Cabe aclarar que la normativa que regula las relaciones sociales al interior de la urbanización cerrada no se encuentra legitimada por la ley expresada en códigos, reglamentos o Constitución Política de los distintos niveles de gobierno. Los reglamentos bajo los que se rigen los residentes de las urbanizaciones cerradas son elaborados e instrumentados por integrantes de las mesas directivas. Ejemplo de ello son las decisiones de cierre de calles que cuentan con código postal, que aparecen en planos y guías oficiales y que, al ser cerradas, contravienen los reglamentos de ordenamiento territorial, como el Bando Municipal o los Planes de Desarrollo Urbano, entre otros. 
decide qué hacer dentro de su propiedad. No obstante, tal argumento no justifica las acciones que violentan la legalidad al limitar el acceso a lo que fue entendido y creado como espacio público: la calle. Con esto nos referimos a las acciones que lleva a cabo la ciudadanía para controlar la circulación peatonal y vehicular con el argumento de la inseguridad, lo que induce a colocar dispositivos como plumas que impiden el libre tránsito o jardineras sobre los carriles laterales de las calles para controlar el acceso, y limitar el aforo de varios a un solo carril. En estos casos, estas calles pierden el carácter público que legalmente tienen.

Por su parte, las relaciones sociales en estos espacios también sufren profundas transformaciones. De acuerdo con las entrevistadas, en muchos casos se ha reducido de manera notable el trato amable y cordial entre los vecinos. Por ejemplo, el tradicional saludo que se lleva a cabo entre vecinos parece ser que ya no es muy importante. El sentimiento de solidaridad también ha sufrido cambios, además de generalizarse una profunda desconfianza del adentro con respecto al afuera. Incluso entre algunos de los mismos residentes, el sentimiento de miedo que se ha acentuado en todo el país se hace patente en los espacios que habitan y ha adquirido relevancia significativa. Finalmente, la apatía y falta de interés por el otro también es notoria en las urbanizaciones cerradas.

Al mismo tiempo, el simbolismo que la calle encerraba, principalmente como espacio de socialización y advenimiento social, se ha transformado. Algunos residentes de los conjuntos urbanos cerrados asocian más la calle a un espacio de peligro, en el cual el ciudadano se encuentra expuesto a una serie de riesgos y amenazas físicas y morales. Para el primer caso se hace referencia a acciones como asaltos y lesiones al cuerpo por cualquier medio; el segundo caso se vincula con agresiones verbales. De ahí que estén completamente de acuerdo en que se privaticen las calles, pues esta acción es vista como una medida de seguridad para ellos y sus familias. Lo mismo sucede con los parques y jardines públicos, lugares que - según los entrevistados - concentran asaltantes, drogadictos, alcohólicos, e incluso albergan la prostitución, con lo que se ha perdido el sentido original para el que fueron creados. Bajo esta argumentación, la totalidad de las entrevistadas aprueba que los conjuntos urbanos cuenten con sus propios espacios recreativos y que estos sean de uso exclusivo de los residentes, para que ellos y sus hijos se encuentren mejor protegidos y aislados de la amenaza externa.

En este sentido, la exclusión y segregación, componentes que caracterizan las urbanizaciones cerradas de Metepec y definen nuevas formas de relacionarse socialmente tanto hacia adentro como hacia afuera, se hacen más notorias cuando se construyen conjuntos urbanos residenciales para población de ingreso alto que se encuentran próximos a sectores de población marginados. Las distinciones, la exclusión y la desconfianza son profundas e insalvables entre estos grupos.

\section{Conclusión}

De este trabajo se pueden desprender algunos resultados en torno al objetivo planteado. El primero de ellos dice relación con el acelerado crecimiento demográfico 
del municipio, y con ello, el crecimiento urbano que se hace presente en el mismo. Dicho crecimiento se caracteriza por la incesante construcción de urbanizaciones cerradas destinadas al comercio, servicios y vivienda. Para el caso de la vivienda cerrada, en el municipio de Toluca se construyó en veinte años alrededor de 115 inmuebles con características de encerramiento. La tendencia en la construcción de espacios cerrados reconfiguró la imagen urbana del municipio, al constituirla como de encerramiento. Tal condición se ve acompañada de una diversidad de dispositivos de seguridad, incluidas bardas perimetrales, casetas de vigilancia, protección privada, rejas, alambres electrificados, cámaras de circuito cerrado, entre otros.

Con la presencia de las urbanizaciones cerradas se pudo identificar un cambio en el sentido tradicional del espacio público. Es decir, los lugares que fueron entendidos como un bien público - la calle, parques y jardines-, en el contexto de la urbanización cerrada adquirieron otro significado: el de uso exclusivo. Al mismo tiempo, el sentido de algunos espacios privados también sufrió cambios. Ello ha afectado principalmente a las plazas comerciales, áreas a las que la población ha dado un sentido de espacio público, al utilizarlas como puntos de reunión, socialización, recreación y diversión. En ambos espacios - los conjuntos residenciales cerrados y las plazas comerciales- se identificó una redefinición de las expresiones físicas de la ciudad y de las relaciones sociales entre sus habitantes y las nuevas manifestaciones urbanas.

Para el caso de la vivienda cerrada, las relaciones sociales sufren cambios significativos, pues se pudo apreciar que en esos espacios se acentúa la conducta individualista y excluyente que debilita los sentimientos de solidaridad con el grupo, y este solo se hace presente en forma de compromiso impuesto por las mismas normas y códigos que regulan la interacción social al interior de las urbanizaciones cerradas, o solo si algún fenómeno externo amenaza la grupalidad. OEURE

\section{Referencias bibliográficas}

Alsina, R. \& Medina, P. (2006). Posmodernidad y crisis de identidad. Revista Cientifica de Información y Comunicación, 3, 126-146. En http://www.ic-journal.org/data/downloads/12650385935rodrigo-alsina.pdf

Bauman, Z. (2007). Miedo líquido. Las sociedades contemporáneas y sus temores. Madrid: Paidós.

Blakely, E. J. \& Gail S. M. (2002, septiembre). Comunidades fortificadas: Amurallamiento y enrejamiento de los suburbios estadounidenses. EURE, 28(84), 145-147. En http://wwwscielo. cl/scielo.php. doi: 10.4067/S0250-71612002008400009

Blakely, E. J. \& Snyder, M. G. (1997). Fortress America: Gated communities in the United States. Washington D.C.: Brookings Institution Press-Lincoln Institute of Land Policy

Borsdorf, A. \& Hidalgo, R. (2009, March). The fragmented city. Changing patterns in Latin American cities. The Urban Reinventors Online Journal, 3(09), 1-18. En http://www.urbanreinventors.net/3/borsdorfhidalgo/borsdorfhidalgo-urbanreinventors.pdf 
Becerril-Sánchez, Méndez, Garrocho | Urbanizaciones cerradas y transformaciones... | CEURE

Cabrales, L. \& Canosa, E. (2001, enero). Segregación residencial y fragmentación urbana: los fraccionamientos cerrados en Guadalajara. Espiral, 7(20), 223-253. En http://redalyc.uaemex. $\mathrm{mx} / \mathrm{pdf} / 138 / 13802008 . \mathrm{pdf}$

Caldeira, T. (2000). City of Walls. Crime, Segregation and Citizenship in Sao Paulo. Berkeley and Los Angeles, CA: University of. California Press.

Callejón, D. (2005, junio). Del cuerpo, el arte y el aula. Red visual, 3. Recurso online. En http://www. redvisual.net/n5/n3/articulos/art5.htm

Callejón, D. \& Granados, I. (2004, diciembre). Deslumbrados, atrapados, construidos. Del diálogo y el tiempo para una mirada sana, para la construcción personal en la escuela. Red visual, 2. En http://www.redvisual.net/n5/n2/art7.htm

Chambers, I. (1994). Migración, cultura, identidad. Buenos Aires: Amorrortu.

Duhau, E. \& Giglia, A. (2004). Conflictos por el espacio y orden urbano. Estudios Demográficos y Urbanos, 19(56), 257-288. En http://codex.colmex.mx:8991/exlibris/aleph/a18_1/apache_media/YSV53C3DIEV7ND6EQYVMU4XT1FLSE1.pdf

Duhau, E. \& Giglia, A. (2008). Las reglas del desorden: Habitar la metrópoli. México, D.F.: Siglo Veintiuno/Universidad Autónoma Metropolitana, Unidad Azcapotzalco.

Enríquez, A. (2007). Segregación y fragmentación en las nuevas ciudades para el turismo. Caso Puerto Peñasco, Sonora, México. Topofilia: Revista de Arquitectura, Urbanismo y Ciencias Sociales. Número Especial. Primer Coloquio Internacional: Ciudades del Turismo. En http://www. topofilia.net/

García, A. (2004). Miedo y privatización de los espacios públicos: ¿Hacer o deshacer la ciudad? En O. Gutiérrez (Coord.), La ciudad y el miedo. VII Coloquio de Geografia Urbana, Grupo de Geografía Urbana, Grupo de Geografia Urbana de la Asociación de Geógrafos Españoles. Gerona, Cataluña: Universitat de Girona.

Garrocho, C. \& Campos, J. (2009). La estructura policéntrica del empleo en el Área Metropolitana de Toluca, 1994-2004. En G. Aguilar \& I. Escamilla (Coords.), Periferia urbana, deterioro ambiental y reestructuración metropolitana. México, D.F.: Universidad Nacional Autónoma de México/Porrúa.

Hidalgo, R. (2004, diciembre). De los pequeños condominios a la ciudad vallada: Las urbanizaciones cerradas y la nueva geografía social en Santiago de Chile (1990-2000). EURE, 30(91), 29-52. En http://www.eure.cl/wp-content/uploads/2004/12/EURE_91_02_HIDALGO.pdf

Janoschka, M. (2002). Urbanizaciones privadas en Buenos Aires: ‘hacia un nuevo modelo de ciudad latinoamericana? En L. F. Cabrales, Ciudades cerradas - países abiertos. Guadalajara: Universidad de Guadalajara/Unesco.

Janoschka, M. \& Glasze, G. (2003). Urbanizaciones cerradas: un modelo analítico. Ciudades, 59 (julio-septiembre), 9-20, RNIU. En http://michael-janoschka.de/pdfs/Janoschka,\%20Michael\%20(2003)_Urbanizaciones\%20cerradas_un\%20modelo\%20anal\%C3\%ADtico.pdf

López, L. \& Rodríguez, I. (2005). Evidencias y discursos del miedo en la ciudad: casos mexicanos. Scripta Nova, Revista Electrónica de Geografía y Ciencias Sociales, 9(194). En http://www. ub.edu/geocrit/sn/sn-194-54.htm

Low, S. M. (2000). The edge and the center: Gated communities and the discourse of urban fear. American Anthropologist, 103(1), 45-58. URL estable: http://www.jstor.org/stable/683921 
Prévot, M. (2008, diciembre). Buenos Aires: la fragmentación en los intersticios de una sociedad polarizada. EURE, 34(103), 73-92. En http://www.eure.cl/wp-content/uploads/2008/12/ EURE_103_04_PREVOT.pdf

Reig, D. (2009). Facebook y Twitter: Convergencia y proceso de apropiación en las Redes Sociales. Blog El Caparazón. En http://www.dreig.eu/caparazon/2009/03/22/facebook-twittercultura-redes-sociales/

Rodríguez, I. (2002). Urbanizaciones cerradas en América Latina. Ciudad y Territorio. Estudios territoriales, 133-134 (otoño-invierno), 500-525.

Rodríguez, I. (2004). "Privatopía” versus ciudad pública, la materialización del miedo en el espacio urbano. [Ponencia y relatoría]. En O. Gutiérrez (Coord.), La ciudad y el miedo. VII Coloquio de Geografia Urbana, Grupo de Geografia Urbana de la Asociación de Geógrafos Españoles (pp. 127-152). Gerona, Cataluña: Universitat de Girona.

Rodríguez, I. (2007). La clonación del paisaje de la exclusión. En I. Rodríguez Chumillas \& E. Méndez Sáiz Eloy, Paisajes y arquitectura de la exclusión. México, D.F.: Ediciones UAM (Universidad Autónoma Metropolitana), Colección de Estudios №. 121.

Roitman, S. (2004, diciembre). Urbanizaciones cerradas: estado de la cuestión hoy y propuesta teórica. Revista de Geografía, 32, 5-19. En http://www.geo.uc.cl/html/revista/PDF/RGNG_N32/ art01.pdf

Sabatini, F., Cáceres, G. \& Cerda, J. (2001, diciembre). Segregación residencial en las principales ciudades chilenas: tendencias de las últimas tres décadas y posibles cursos de acción. EURE, 27(82), 21-42. En http://redalyc.uaemex.mx/pdf/196/19608202.pdf

Safa, B. (2002). Construir mundos, levantar muros y preservar patrimonios: condominios y fraccionamientos cerrados. En L. F. Cabrales, Latinoamérica: paises abiertos, ciudades cerradas (pp. 145-176). Guadalajara: Universidad de Guadalajara/Organización de las Naciones Unidas para la Educación, Ciencia y Cultura (Unesco).

Salcedo, R. (2002). El espacio público en el debate actual: Una reflexión crítica sobre el urbanismo postmoderno. EURE, 28(84), 5-19. En http://www.eure.cl/wp-content/uploads/2002/09/ EURE_84_01_SALCEDO.pdf

Salgado, C. (2007, septiembre). Investigación cualitativa, diseños: evaluación del rigor metodológico y retos. LIBERABIT, 13, 71-78. En http://www.revistaliberabit.com/liberabit13/8_ana_cecilia.pdf

Sampieri, R. (2002). Metodología de la investigación (2a ed.). México, D.F.: McGraw-Hill.

Sampieri, R. (2004). Metodología de la investigación (3a ed.). México, D.F.: McGraw-Hill.

Svampa, M. (2001). Los que ganaron. La vida en los countries y barrios privados. Buenos Aires: Biblos.

Thuillier, G. (2005, agosto). El impacto socioespacial de las urbanizaciones cerradas: el caso de la región metropolitana de Buenos Aires. EURE, 31(93), 5-20. En http://www.eure.cl/wpcontent/uploads/2005/09/EURE_93_01_THUILLIER.pdf

Torres, H. (2001, mayo). Cambios socioterritoriales en Buenos Aires durante la década de 1990. EURE, 27(80), 33-56. En http://www.eure.cl/wp-content/uploads/2001/05/EURE_80_02_ TORRES.pdf 
Becerril-Sánchez, Méndez, Garrocbo | Urbanizaciones cerradas y transformaciones... | CEURE

\section{Documentos oficiales}

Gobierno del Estado de México (GEM). (2006). Plan de Desarrollo Municipal de Metepec 2006 -2009 [s.n]. México: Autor.

Gobierno del Estado de México (GEM). (2008). Registro Estatal de Desarrollo Urbano [s.n]. México: Autor.

Gobierno del Estado de México (GEM). (2009). Plan de Desarrollo Municipal de Metepec 2009-2012 [s.n]. México: Autor.

H. Ayuntamiento de Metepec. Secretaría de Desarrollo Urbano, Registro Estatal de Desarrollo Urbano y la Dirección de Desarrollo Urbano y Obras Públicas del municipio de Metepec. (2008). Inventario de conjuntos habitacionales [s.n]. México: Secretaría de Desarrollo Urbano, Registro Estatal de Desarrollo Urbano y la Dirección de Desarrollo Urbano y Obras Públicas del municipio de Metepec.

Instituto Nacional de Estadística, Geografía e Informática (INEGI). (1990). XI Censo General de Población y Vivienda [s.n]. México: Autor. En http://www.inegi.org.mx/est/contenidos/ proyectos/ccpv/cpv1990/default.aspx

Instituto Nacional de Estadística, Geografía e Informática (INEGI). (2000). XII Censo General de Población y Vivienda [s.n]. México: Autor. En http://www.inegi.org.mx/est/contenidos/ Proyectos/ccpv/cpv2000/default.aspx

Instituto Nacional de Estadística, Geografía e Informática (INEGI). (2010). Censo de Población y Vivienda 2010 [s.n]. México: Autor. En http://www.inegi.org.mx/est/contenidos/proyectos/ccpv/cpv2010/Default.aspx

\section{Páginas de Internet consultadas}

http://www.edomex.gob.mx/sedur/estadisticas/conjuntos-urbanos/Gobierno del Estado de México, Secretaría de Desarrollo Urbano. Archivo de Fraccionamientos de la Secretaría de Desarrollo Urbano 2008. 